\title{
LIDAR MEASUREMENTS OF OZONE IN THE UPPER TROPOSPHERE - LOWER STRATOSPHERE AT SIBERIAN LIDAR STATION IN TOMSK
}

\author{
O. A. Romanovskii ${ }^{12^{*}}$, S.I. Dolgii ${ }^{1}$, V. D. Burlakov ${ }^{1}$, A.A. Nevzorov ${ }^{1}$ and A. V. Nevzorov ${ }^{1}$ \\ ${ }^{1}$ V.E. Zuev Institute of Atmospheric Optics SB RAS, 1 Zuev Square, Tomsk 634021, Russia, roa@iao.ru \\ ${ }^{2}$ National Research Tomsk State University, 36 Lenina Pr., Tomsk 634050, Russia
}

\begin{abstract}
The paper presents the results of DIAL measurements of the vertical ozone distribution at the Siberian lidar station. Sensing is performed according to the method of differential absorption and scattering at wavelength pair of $299 / 341 \mathrm{~nm}$, which are, respectively, the first and second Stokes components of SRS conversion of 4th harmonic of Nd:YAG laser $(266 \mathrm{~nm})$ in hydrogen. Lidar with receiving mirror $0.5 \mathrm{~m}$ in diameter is used to implement sensing of vertical ozone distribution in altitude range of $6-16 \mathrm{~km}$. The temperature correction of zone absorption coefficients is introduced in the software to reduce the retrieval errors.
\end{abstract}

\section{INTRODUCTION}

Ozone plays a key role as a shield against hard UV solar radiation for all living on our planet. Also, it is an important climate-forcing agent, which plays a significant role in thermal balance of the planet. Activation of the processes of destruction of stratospheric ozone layer, formation and spread of ozone anomalies ("ozone holes") over Antarctica, Europe, and Siberia necessitated arrangement of planetary-scale monitoring. This has led to creation of network of ground-based ozonometer stations, which measure the total ozone (TO) content with the help of different spectrophotometers (foreign instruments such as Dobson, Junker, and Brewer spectrophotometers, and national instrument such as $\mathrm{M}-124$ ozonometer). In addition, information on TO is inferred from satellite (TOMS and other) measurements. Laser sensing of ozonosphere had been regular at a number of observatories since the second half of 1980s. It provides information on vertical ozone distribution (VOD), successfully complicating a similar information obtained in situ with the help of ozonesondes, as well through "onion-peeling" approach from satellites (SAGEII, Terra-Aqua, etc.) [1]. The multiyear lidar observations of stratospheric ozone had made it possible to obtain information on climatology of ozonosphere, especially above $30 \mathrm{~km}$, where ozonesonde data become unrepresentative. The lidar measurements of VOD are performed on the basis of method of differential absorption of backscattered energy of laser radiation in UV wavelength range of $240-360 \mathrm{~nm}$ (the so-called Hartley-Huggins band). As a rule, for sensing the stratospheric ozone, the fundamental frequency of excimer $\mathrm{XeCl}$ laser $\left(308 \mathrm{~nm}\right.$ ) is used as $\lambda_{\text {on }}$, where absorption of sensing radiation by ozone is strong. At the same time, as a reference frequency (with weak absorption) $\lambda_{\text {off, }}$ researchers use either the first component of its SRS conversion in hydrogen $(353 \mathrm{~nm})$, with efficiency of conversion reaching $40 \%$, or the third harmonic of $\mathrm{Nd}: Y A G$ laser $(355 \mathrm{~nm})$, the energy of which may reach more than $100 \mathrm{~mJ}$.

Long-term period of lidar observations of stratospheric ozone (since 1989) at the measurement complex Siberian Lidar Station (SLS), V.E. Zuev Institute of Atmospheric Optics, Siberian Branch, Russian Academy of Sciences (Tomsk: $56.5^{\circ} \mathrm{N} ; 85.0^{\circ} \mathrm{E}$ ) [2] showed that the part, most significant for studying the ozonosphere, is located in the lower stratosphere, where ozone is subject to the effect of dynamic factor. This part totally determines the TO variations in atmospheric column. Poorly studied scenarios of stratosphere-troposphere exchange, deformation of ozonosphere by jet streams, and formation of fine tongue-like structure of ozone layer also develop in this part. However, higher concentration sensitivity of lidar measurements is required to perform these studies in altitude 
ranges of upper troposphere - lower stratosphere, thus necessitating passage to shorter-wavelength region of UV spectrum, where ozone absorption cross section is greater.

\section{SELECTION OF WAVELENGTHS}

Excimer $\mathrm{KrF}$ laser $(248 \mathrm{~nm})$ or the fourth harmonic of Nd:YAG laser $(266 \mathrm{~nm})$ in combination with technique of SRS conversion in $\mathrm{H}_{2}, \mathrm{D}_{2}, \mathrm{CO}_{2}$, and other gases [3-6] are usually used for tropospheric measurements of ozone. Hydrogen and deuterium are most widespread, in this regard. A possible set of wavelengths, corresponding to the 1st, 2nd, and 3rd Stokes (C) frequencies of SRS conversion in $\mathrm{H}_{2}, \mathrm{D}_{2}$, and $\mathrm{CO}_{2}$, is presented in Table.

\begin{tabular}{|c|c|c|c|}
\hline \multirow{2}{*}{$\begin{array}{l}\text { Pumping } \\
\text { radiation }\end{array}$} & \multicolumn{3}{|c|}{$\begin{array}{l}\text { Wavelengths }(\mathrm{nm}) \text { corresponding } \\
\text { to the Stokes frequencies }(C) \text { of the } \\
\text { SRS conversion }\end{array}$} \\
\hline & $\begin{array}{c}\text { in } \mathrm{H}_{2} \\
\mathrm{C} 1 \quad \mathrm{C} 2\end{array}$ & $\begin{array}{c}\text { In } \mathrm{D}_{2} \\
\mathrm{C} 1 \mathrm{C} 2 \mathrm{C} 3\end{array}$ & $\begin{array}{l}\text { in } \mathrm{CO}_{2} \\
\mathrm{C} 2 \quad \mathrm{C} 3 \\
\end{array}$ \\
\hline $\begin{array}{c}\mathrm{Nd}: \mathrm{YAG}, \\
266 \mathrm{~nm} \\
\mathrm{KrF}, \\
248 \mathrm{~nm}\end{array}$ & $\begin{array}{l}299341 \\
277313\end{array}$ & $\begin{array}{c}289316 \\
268291319\end{array}$ & $\begin{array}{ll}287 & 299\end{array}$ \\
\hline
\end{tabular}

Diverse wavelength combinations are used in different altitude ranges of the troposphere and lower stratosphere. For instance, the wavelength pairs $289 / 316$ and $287 / 299 \mathrm{~nm}$ make it possible to obtain ozone profile up to the heights of about

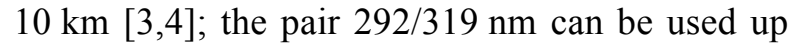
to the heights of $14-16 \mathrm{~km} \mathrm{[5];} \mathrm{and} \mathrm{the} \mathrm{pairs}$ $277 / 313$ and $292 / 313 \mathrm{~nm}$ can be used up the heights of 8-12 and $15 \mathrm{~km}$, respectively [6].

The wavelength $\lambda_{\text {on }}=299 \mathrm{~nm}$ lies in the region of ozone absorption band with absorption cross section $\sigma_{299}=4.4 \cdot 10^{-19} \mathrm{~cm}^{2}$, a factor of 3 larger than the absorption cross section at the wavelength of $308 \mathrm{~nm}: \sigma_{308}=1.4 \cdot 10^{-19} \mathrm{~cm}^{2}$. The maximal height of sensing is determined primarily by the range from which the signal at $\lambda_{\text {on }}$ is recorded, which is always shorter than the range from which the signal at $\lambda_{\text {off }}$ is recorded, due to stronger absorption by ozone. From this viewpoint, $\lambda_{\text {on }}=299 \mathrm{~nm}$ is more preferable than 277 or $292 \mathrm{~nm}$. Wavelengths 299 and 341 are implemented in one sensing beam (in one SRS cell), in contrast to, e.g., pair $292 / 313 \mathrm{~nm}$. It is noteworthy that system on the basis of hydrogenfilled SRS cell is cheaper than deuterium-filled cell. It is also important to remember about technical feasibility of spectral separation, during reception, of signals at closely lying wavelengths. To study the vertical ozone distribution in the upper troposphere - lower stratosphere, we developed and put into measurement mode a lidar, as part of SLS, for measuring the ozone concentration in the upper troposphere - lower stratosphere [7]. Sensing is performed according to the method of differential absorption and scattering at wavelength pair of $299 / 341 \mathrm{~nm}$, which are, respectively, the first and second Stokes components of SRS conversion of 4th harmonic of Nd:YAG laser $(266 \mathrm{~nm})$ in hydrogen. Lidar with receiving mirror $0.5 \mathrm{~m}$ in diameter is used to implement sensing of vertical ozone distribution in altitude range of 6-16 km.

\section{LIDAR FOR SENSING THE VERTICAL OZONE DISTRIBUTION IN THE UPPER TROPOSPHERE STRATOSPHERE \\ LOWER}

Figure 1 presents the block-diagram of the developed lidar.

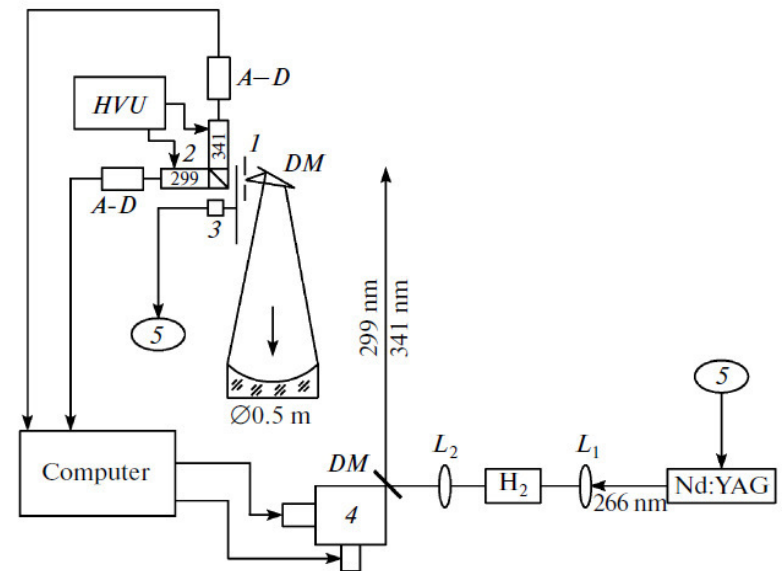

Fig. 1. Block-diagram of the lidar: (1) field diaphragm, (2) cell for spectral selection with a PMT, (3) mechanical shutter, (4) automated adjustment unit of the rotating output mirror, (5) system for synchronizing the shutter operation time and the moment of emission of laser pulses, $(D M)$ deflecting mirrors, (Nd:YAG) solid-state laser, $\left(\mathrm{H}_{2}\right)$ SRS conversion cell with $\mathrm{H}_{2},(A-D)$ amplifiersdiscriminators, (HVU) high-voltage power supply units for the PMT, and $\left(L_{1}, L_{2}\right)$ lenses. 
As the source of laser radiation, we use the 4th harmonic $(266 \mathrm{~nm})$ of fundamental frequency of Nd:YAG laser (model LS-2134UT, LOTIS TII firm, Minsk) with its subsequent SRS conversion in hydrogen to the first $(299 \mathrm{~nm})$ and second $(341 \mathrm{~nm})$ Stokes components.The vertical ozone profiles are retrieved from lidar signals with the help of universal software [8], which allows the altitude profiles of ozone concentration to be calculated according to the method of differential absorption and scattering for three wavelength pairs $272 / 289 \mathrm{~nm}, 299 / 341 \mathrm{~nm}$, and $308 / 353 \mathrm{~nm}$. The software applies linear smoothing for both input lidar data and for retrieval results. Linear smoothing (smoothing by sliding average) is a well-known procedure, widely used for processing the experimental data in different natural science regions. Linear smoothing is a particular case of digital filtering, possessing random signal error, filter with rectangular window, and unit weighting coefficients.

The software permits us: to read off lidar data and save the retrieval results in ASCII format; smooth the lidar signals and retrieval results using sliding mean. The software incorporates temperature correction of ozone absorption coefficients to reduce the retrieval errors. When lidar signals are retrieved at sensing wavelengths $272 / 289 \mathrm{~nm}$ and $299 / 341 \mathrm{~nm}$, large aerosol concentrations in the altitude range of $0-20 \mathrm{~km}$ should be taken into consideration; therefore, aerosol correction is accounted for in the software. Seasonal model values of altitude distribution of temperature and molecular backscattering coefficient for midlatitude winter and summer are introduced in the software for the calculations.

\section{RESULTS OF MEASUREMENTS}

Examples of retrieved profiles of vertical ozone distribution are presented in Figure 2 (a November 2014, b - January-February 2015).

Figure 2 presents the retrieved profiles of ozone concentration for November 2014 and JanuaryFebruary 2015 and compares them with Krueger midlatitude model [9] and IASI satellite data. The retrieved and model profiles quite well coincide, while deviations from IASI satellite data are quite natural for ozone dynamics in separate observation days.

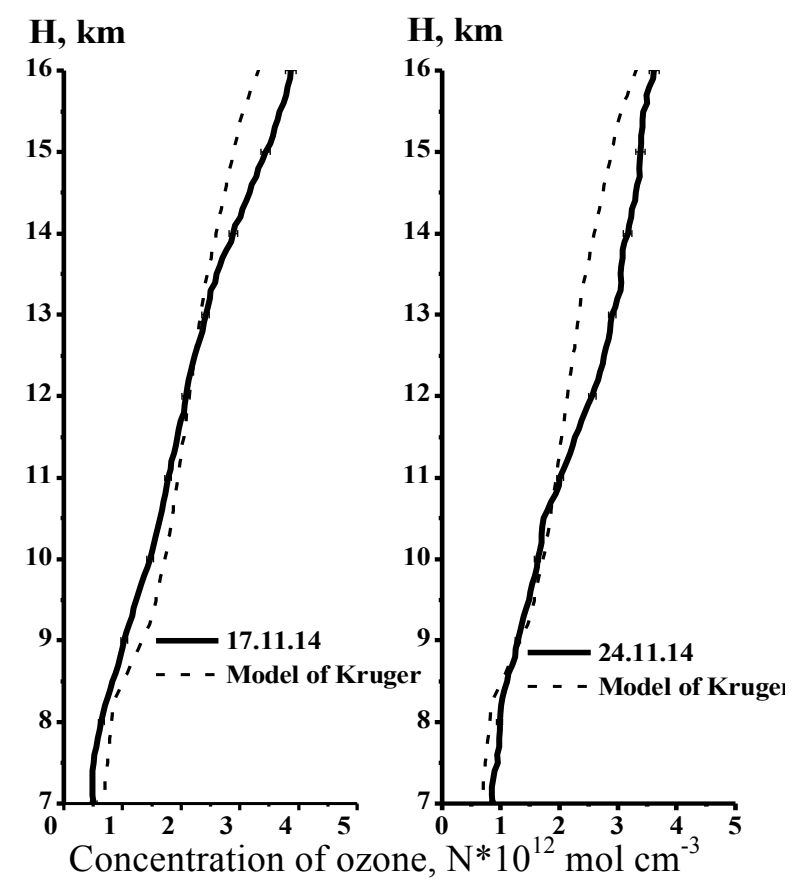

a)
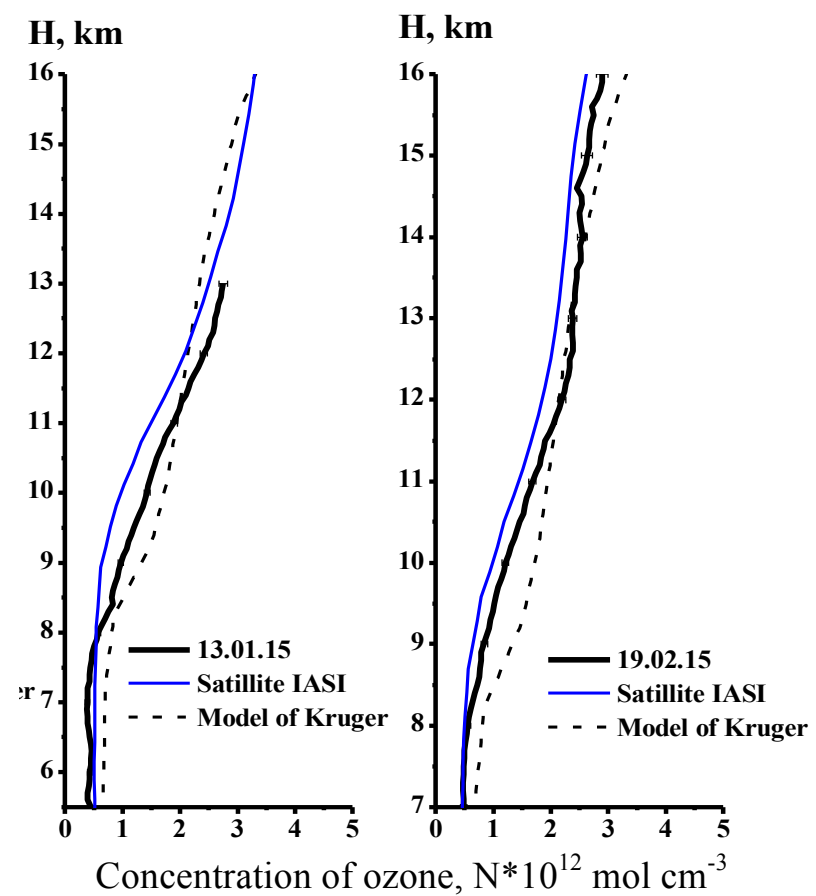

b)

Figure 2 - Retrieved vertical profiles of ozone concentration at wavelengths $299 / 341 \mathrm{~nm} \mathrm{(a} \mathrm{-}$ November 2014, b - January-February 2015) compares them with Krueger midlatitude model and IASI satellite data. 


\section{CONCLUSIONS}

Lidar measurements at wavelengths 299 and $341 \mathrm{~nm}$ agree with model estimates and satellite (IASI) observations, which indicate acceptable accuracies of ozone sensing in the altitude range of about 6-16 kткм. We can also note that, for ozone sensing in the altitude range of $5-20 \mathrm{~km}$, lidar on the basis of $\mathrm{Nd}$ :YAG laser is more preferable than lidar on the basis of excimer $\mathrm{KrF}$ laser which is more costly, more complex in exploitation, needs especially pure gases for working mixture, frequent purification or replacement of resonator optics.

\section{ACKNOWLEDGEMENTS}

This work was supported in part by the Ministry of Science and Education of the Russian Federation (Agreement No. 14.604.21.0100 (RFMEFI60414X0100)), the Russian Science Foundation (Agreement no. 14-27-00022), The President of the Russian Federation (Grant NSh4714.2014.5).

\section{REFERENCES}

\section{[1] http://sage.nasa.gov/SAGE2/}

[2] Burlakov, V.D., Dolgii, S.I., Nevzorov, A.V., 2004, Modification of the measuring complex at the Siberian Lidar Station. Atmospheric and oceanic optics. 17 (10), 756-762.

[3] Galani, E., Balis, D., Zanis, P., Zerefos, C., Papayannis, A., Wemli, H., and Gerasopoulos, E., 2003, Observations of stratosphere-to-troposphere transport events over the eastern Mediterranean using a ground-based lidar system. J. Geophys. Res. 108, D12. P.STA12/1-STA12/10.

[4] Masahisa Nakazato, Tomohiro Nagai, Tetsu Sakai, and Yasuo Hirose, 2007, Tropospheric ozone differential-absorption lidar using stimulated Raman scattering in carbon dioxide. Appl. Opt. 46 (12), 2269-2279.

[5] Bukreev, V.S., Vartapetov, S.K., Veselovskii, I.A., Galustov, A.S., Kovalev, Yu.M., Prokhorov, A.M., Svetogorov, E.S., Khmelevtsov, S.S., Li, Ch.Kh., 1994, Lidar system for sensing the stratospheric and tropospheric ozone on the basis of excimer lasers. Quantum Electronics. 21 (6), 591- 596.

[6] Eisele, H., H.E. Scheel, R. Sladkovic, and T. Trickl, 1999, High resolution lidar measurements of stratosphere-troposphere exchange. J. Atmos. Sci., 56 (3), 319-330.

[7] Burlakov, V.D., Dolgii, S.I., Makeev, A.P., Nevzorov, A.V., Romanovskii, O.A., Kharchenko, O.V, 2010, A differential-absorption lidar for ozone sensing in the upper atmospherelower stratosphere. Instruments and Experimental Techniques. 2010. 53 (6). 886-889.

[8] Nevzorov, A.V., Nevzorov, A.A., Romanovskii, O.A., 2014, Software for retrieving the ozone altitude profiles from data of atmospheric laser sensing. Proc. SPIE. 9292, 92923L. doi:10.1117/12.2074718.

[9] Krueger A.J., Minzner R.A., 1976, A midlatitude ozone model for the 1976 U.S. standard atmosphere. J. Geophys. Res., 81 (D24) 44774481. 